\title{
APLIKASI PENGELOLAAN PELAKSANAAN PROYEK BERBASIS WEB PADA CV. PUTERI MURAKATA
}

\author{
Fauzi Yusa Rahman, M.Kom \\ Fakultas Teknologi Informasi, Universitas Islam Kalimantan Muhammad Arsyad Al Banjari Banjarmasin \\ fauziyusarahman@gmail.com
}

\begin{abstract}
CV. Puteri Murakata adalah perusahaan yang bergerak pada bidang general suplier dan kontraktor yang melayani perusahaan menengah dan perusahaan besar, baik swasta dan pemerintahan. Saat ini pengelolaan data pada CV. Puteri Murakata masih dilakukan melalui pembukuan yang ditulis secara manual.

Hal ini tentu saja memiliki banyak kekurangan, komputerisasi merupakan cara tepat untuk mengatasi permasalahan ini. Aplikasi berbasis web untuk menggantikan pekerjaan yang awalnya masih secara manual sekarang menjadi berbasis komputer. Aplikasi tersebut diharapkan dapat mempermudah dan dapat mengatur jalannya proses pengelolaan data pada CV. Puteri Murakata.
\end{abstract}

Kata kunci : Aplikasi, Proyek, Web.

\section{PENDAHULUAN}

CV. Puteri Murakata adalah perusahaan yang bergerak pada bidang general suplier dan kontraktor yang melayani perusahaan menengah dan perusahaan besar, baik swasta dan pemerintahan. CV. Puteri Murakata sebagai perusahaan yang bergerak pada bidang pengadaan barang dan jasa yang di dirikan pada tahun 2013, menyediakan solusi bisnis yang inovatif kepada perusahaan yang menjadi mitra yang man selalu mengutamakan mutu serta kepercayaan demi kelangsungan bisnis yang harmonis dan berkelanjutan.

Saat ini pengelolaan data pada CV. Puteri Murakata masih dilakukan melalui pembukuan yang ditulis secara manual. Hal ini tentu saja memiliki banyak kekurangan yang mungkin mengganggu dalam pengelolaan data, komputerisasi merupakan cara tepat untuk mengatasi permasalahan ini. Aplikasi berbasis web untuk menggantikan pekerjaan yang awalnya masih secara manual sekarang menjadi berbasis komputer. Aplikasi tersebut diharapkan dapat mempermudah dan dapat mengatur jalannya proses pengelolaan data pada CV. Puteri Murakata.

\section{METODE PENELITIAN}

Metode waterfall sering disebut dengan siklus hidup klasik (classic life cycle), dimana hal ini menggambarkan pendekatan yang sistematis dan juga berurutan pada pengembangan perangkat lunak, dimulai dengan spesifikasi kebutuhan pengguna lalu berlanjut melalui tahapan-tahapan perencanaan (planning), permodelan (modeling), konstruksi (construction), serta penyerahan sistem ke para pengguna (deployment), yang diakhiri 
dengan dukungan pada perangkat lunak lengkap yang dihasilkan (Pressman, 2012). Pengembangan metode waterfall memiliki beberapa tahapan yang berurut yaitu: requirement (analisis kebutuhan), design system (desain sistem), coding (pengkodean) \& testing (pengujian), Penerapan Program, pemeliharaan.

Dalam pengembangan sistem ini, ada tahapan yang harus dilakukan. Adapun tahapan tersebut adalah sebagai berikut:

\section{Analisa Sistem}

Dalam membangun aplikasi ini diperlukan perencanaan yang baik agar dihasilkan sistem yang dapat berjalan optimal. Tahap perencanaan ini terbagi atas 2 yaitu:

a. Menentukan tujuan pembuatan aplikasi

Tujuan penelitian ini adalah agar memberikan kemudahan baik bagi pemilik CV maupun administrator untuk melakukan proses pengelolaan proyek, maupun proses pencarian data material dan data karyawan secara cepat dan mudah.

b. Menentukan siapa yang akan menjadi pemakai

Aplikasi pengelolaan proyek ini dipakai oleh administrator dan direktur selaku pemilik CV untuk mengatur gaji pegawai.

2. Perancangan Sistem

Proses perancangan yang baik diperlukan untuk pembuatan program tak terkecuali dalam pembuatan aplikasi yang baik. Perancangan sistem secara terperinci, dilakukan dengan cara:
a. Rancangan Menu
b. Rancangan Database
c. Relasi Antar Tabel
d. Diagram Konteks
e. Data Flow Diagram (DFD)
f. Rancangan Tampilan
g. Rancangan Laporan

Pembuatan aplikasi pelaksanaan proyek ini dibuat menggunakan bahasa pemrograman PHP dan MySQL sebagai pengelola databasenya.

\section{Testing Aplikasi}

Pada tahap ini, dilakukan uji terhadap sistem yang telah selesai dibuat dengan menggunakan modem dan satu buah laptop server, setiap proses pendataan dilakukan langsung pada hosting dan domain yang telah disediakan sebelumnya.

\section{HASIL DAN PEMBAHASAN}

Aplikasi Pengelolaan pelaksanaan proyek berbasis web ini terdiri dari dua level user yang dapat login, yaitu level administrator yang dapat mengatur dan mengelola web dan level direktur yang dapat mengakses form halaman setting jabatan dan halaman setting potongan gaji. Agar dapat dijalankan secara online, dapat menggunakan sewa hosting dan domain yang banyak disediakan secara online.

\subsection{Rancangan Menu}

Rancangan menu pada aplikasi pengelolaan pelaksanaan proyek mempunyai 2 level user, yaitu admin dan direktur. Berikut rancangan menu yang terbentuk:

1. Rancangan Menu Admin
a. Login
b. Home
c. Data Master

1) Data Proyek

2) Belanja Proyek

3) Karyawan

4) Suplier

d. Penggajian

1) Input Penggajian

e. Laporan

1) Lap Mingguan

2) Lap Bulanan 
3) Lap Tahunan

4) Lap Penggajian

f. Profile

1) Acount

2) Logout

2. Rancangan Menu Direktur

a. Login

b. Home

c. Setting
1) Jabatan \& Gaji
2) Potongan
3) Administrator

d. Laporan

1) Lap Mingguan

2) Lap Bulanan

3) Lap Tahunan

4) Lap Penggajian

e. Profile

1) Logout

\subsection{Rancangan Database}

Database dibuat menggunakan database MySQL menggunakan aplikasi PHPMyAdmin dan diberi nama cvputrimurakata, berikut tabel-tabel yang terbentuk:

1. Tabel Admin

2. Tabel Karyawan

3. Tabel Jabatan

4. Tabel Penggajihan

5. Tabel Beli Material

6. Tabel Suplier

7. Tabel Potongan Gaji

8. Tabel Pembangunan

9. Tabel Rancangan Anggaran Material

10. Tabel Progres Proyek

11. Tabel Rancangan Kegiatan

12. Tabel Sub Pekerjaan

\subsection{Relasi Tabel}

Relasi antar tabel digunakan untuk melihat tabel-tabel mana saja yang terhubung dalam aplikasi pengelolaan pelaksanaan proyek pada CV. Puteri
Murakata. Berikut relasi antar tabel yang terbentuk.

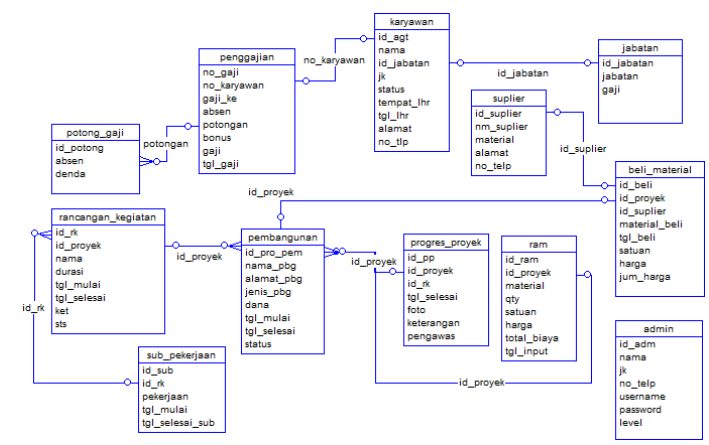

Gambar 1. Relasi Tabel

\subsection{Diagram Konteks}

Diagram konteks dari aplikasi pengelolaan pelaksanaan proyek pada $\mathrm{CV}$. Puteri Murakata ini adalah sebagai berikut:

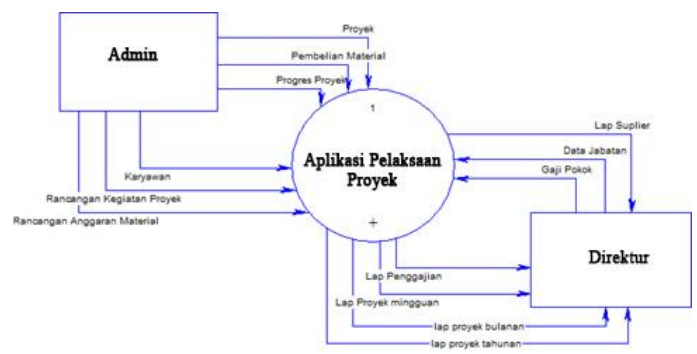

Gambar 2. Diagram Konteks

\subsection{Data Flow Diagram (DFD)}

Data Flow Diagram pada aplikasi pengelolaan pelaksanaan proyek pada $\mathrm{CV}$. Puteri Murakata ini menggambarkan dari mana asal data dan kemana tujuan data yang keluar dari sistem.

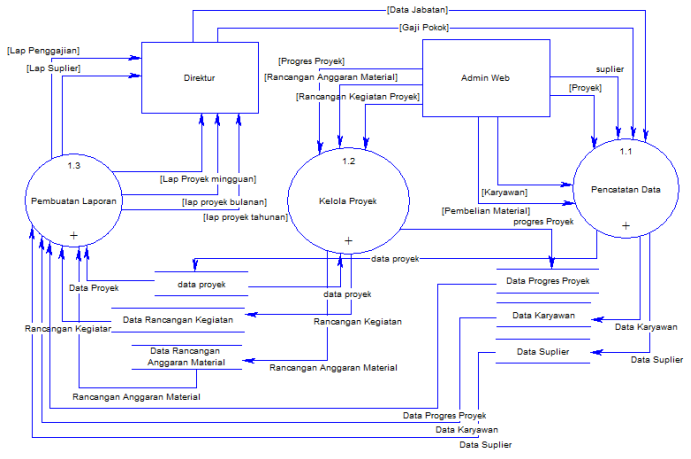

Gambar 3. Data Flow Diagram (DFD) 


\subsection{Rancangan Tampilan}

Rancangan tampilan pada aplikasi pengelolaan pelaksanaan proyek $\mathrm{CV}$. Puteri Murakata terdiri atas dua bagian yaitu rancangan tampilan untuk level user admin dan level user direktur.

1. Rancangan Tampilan Admin

a. Halaman Login Admin

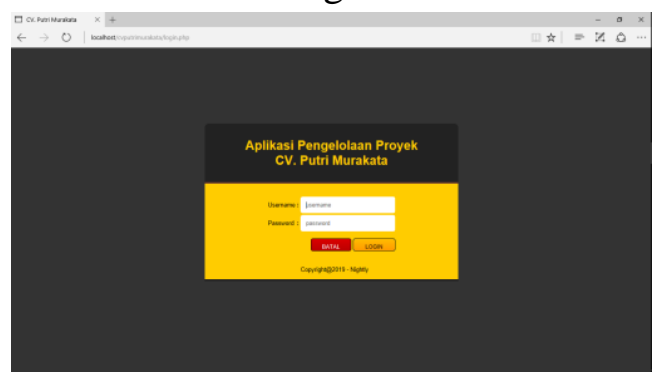

Gambar 4. Halaman Login Admin

b. Halaman Home Admin

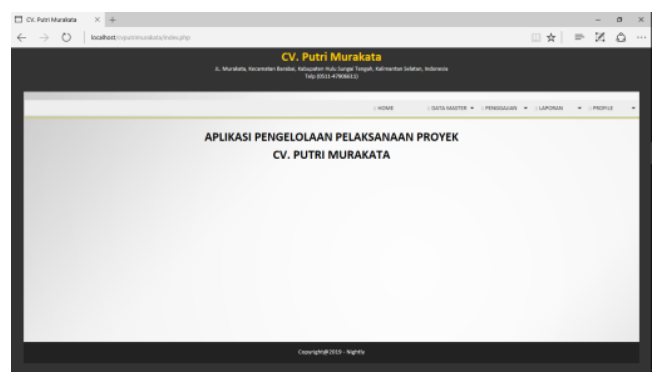

Gambar 5. Halaman Home Admin

c. Halaman Form Data Proyek

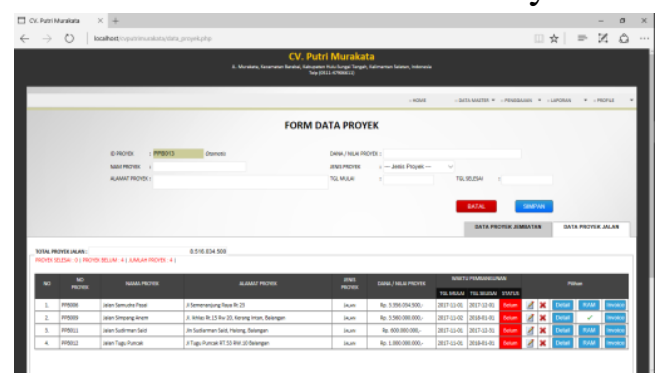

Gambar 6. Halaman Form Data Proyek

d. Halaman Belanja Material Proyek

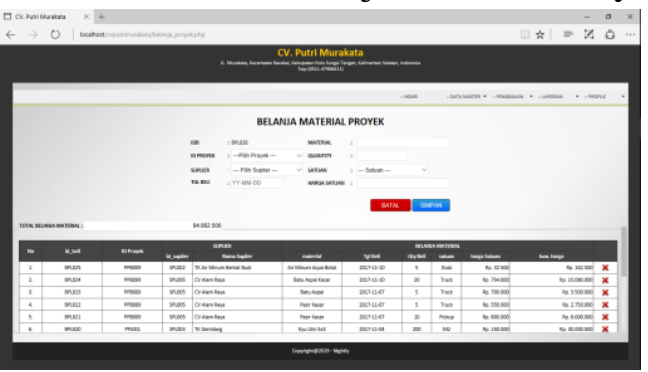

Gambar 7. Halaman Belanja Material Proyek e. Halaman Data Karyawan

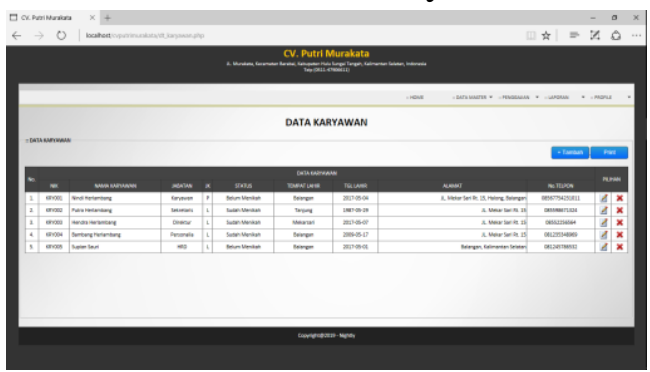

Gambar 8. Halaman Data Karyawan

f. Halaman Data Suplier

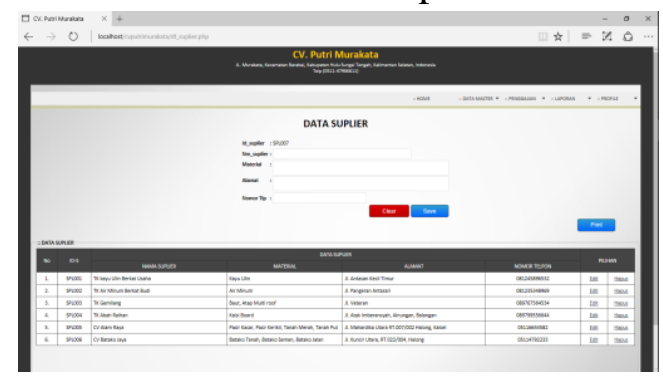

Gambar 9. Halaman Data Suplier

g. Halaman Form Penggajian



Gambar 10. Halaman Form Penggajian

h. Halaman Laporan Proyek Per Minggu

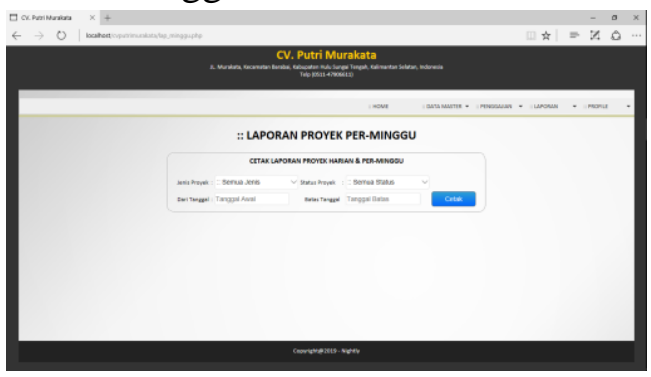

Gambar 11. Halaman Laporan Proyek Per Minggu 
i. Halaman Laporan Proyek Per Bulan



Gambar 12. Halaman Laporan Proyek Per Bulan

j. Halaman Laporan Proyek Per Tahun

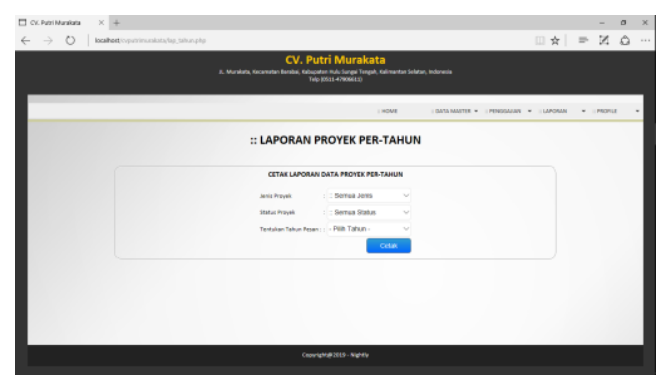

Gambar 13. Halaman Laporan Proyek Per Tahun

k. Halaman Cetak Data Penggajian

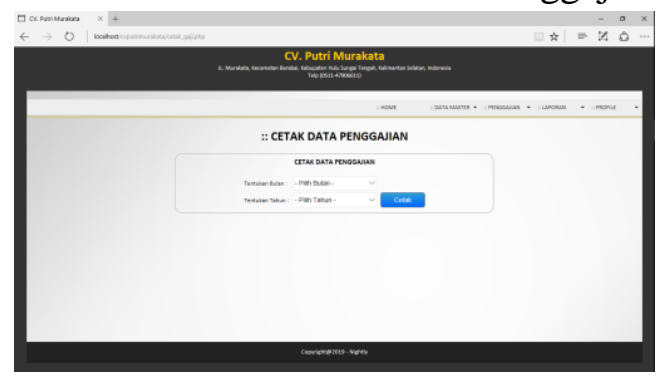

Gambar 14. Halaman Cetak Data Penggajian

1. Halaman Data Profil

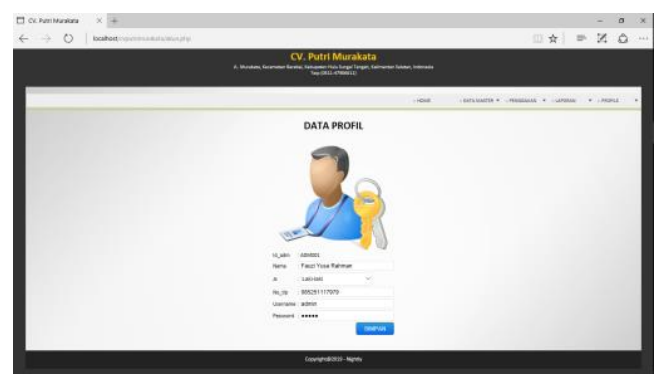

Gambar 15. Halaman Data Profil
2. Rancangan Tampilan Direktur

a. Halaman Login Direktur

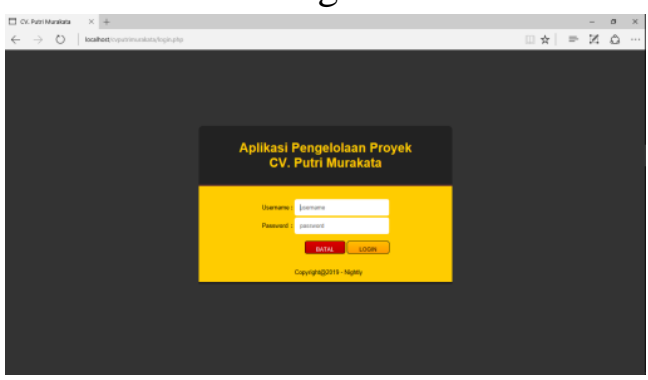

Gambar 16. Halaman Login Direktur

b. Halaman Home Direktur

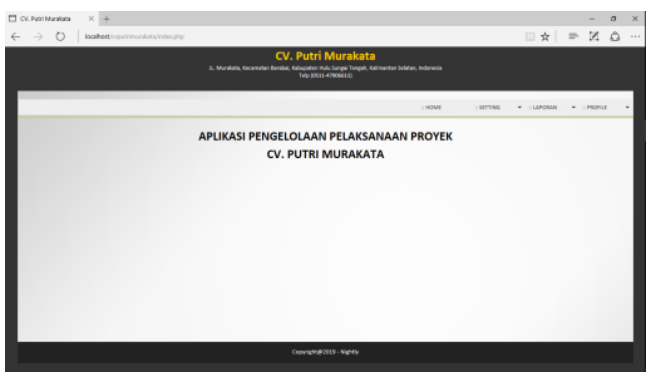

Gambar 17. Halaman Home Direktur

c. Halaman Setting Jabatan

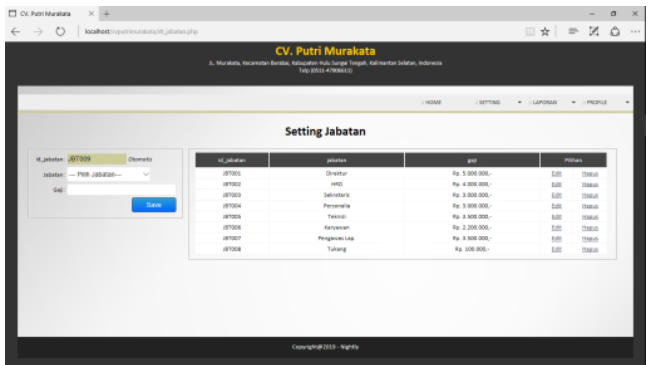

Gambar 18. Halaman Setting Jabatan

d. Halaman Setting Potogan Gaji

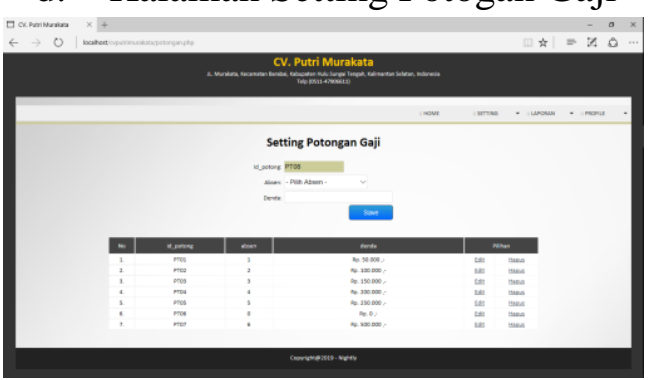

Gambar 19. Halaman Setting Potogan Gaji 
e. Halaman Data Admin

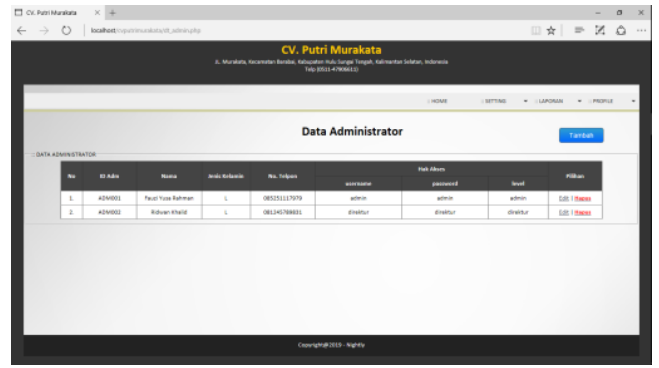

Gambar 20. Halaman Data Admin

f. Halaman Laporan Proyek Per Minggu

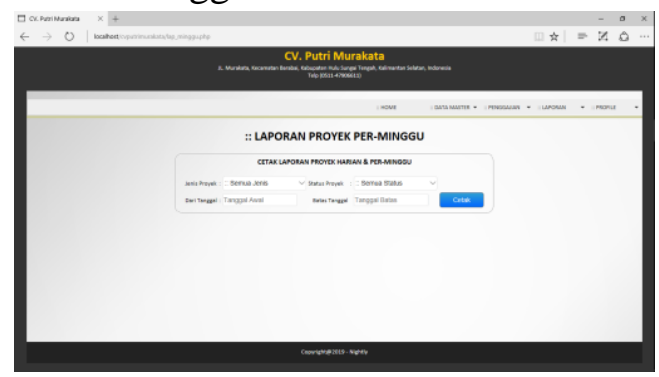

Gambar 21. Halaman Laporan Proyek Per Minggu

g. Halaman Laporan Proyek Per Bulan

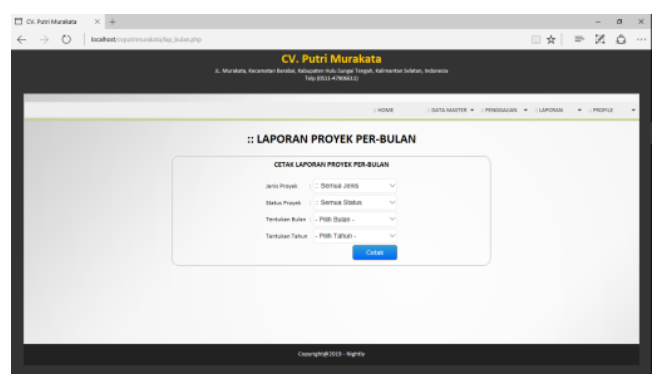

Gambar 22. Halaman Laporan Proyek Per Bulan

h. Halaman Laporan Proyek Per Tahun

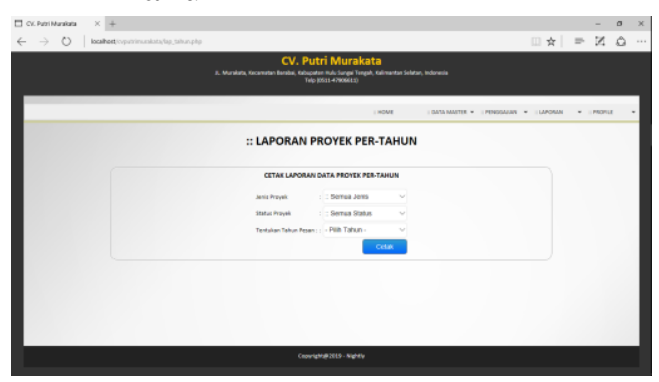

Gambar 23. Halaman Laporan Proyek Per Tahun i. Halaman Cetak Data Penggajian

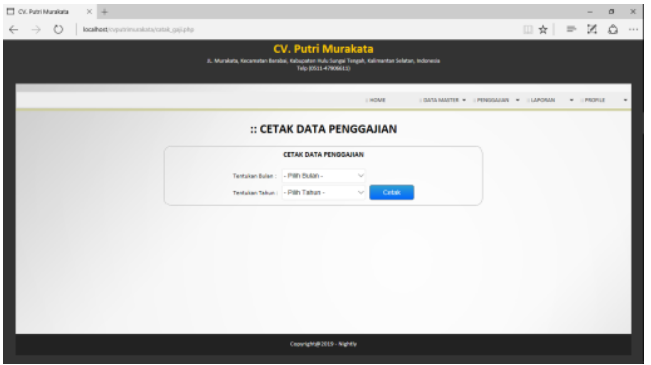

Gambar 24. Halaman Cetak Data Penggajian

\subsection{Rancangan Laporan}

1. Laporan Proyek Per Minggu

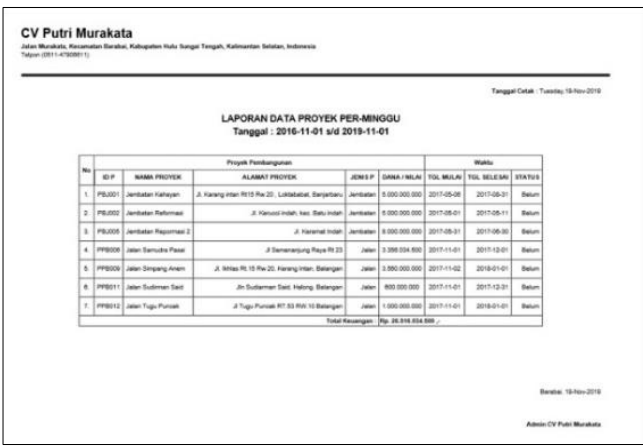

Gambar 25. Laporan Proyek Per Minggu

2. Laporan Proyek Per Bulan

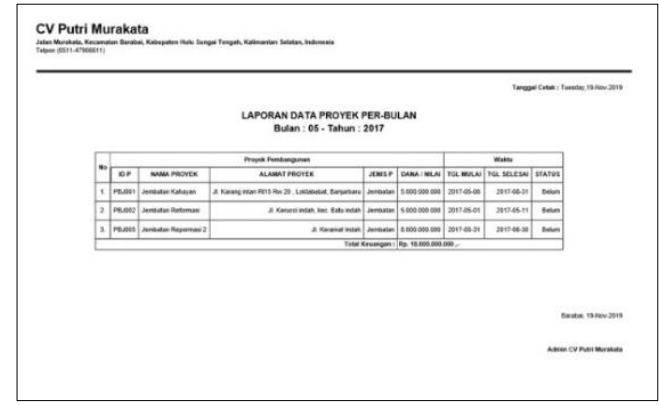

Gambar 26. Laporan Proyek Per Bulan

3. Laporan Proyek Per Tahun

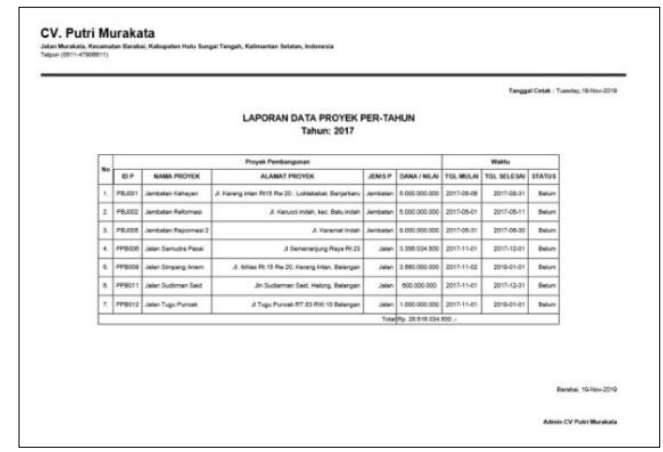

Gambar 27. Laporan Proyek Per Tahun 
4. Laporan Data Penggajian

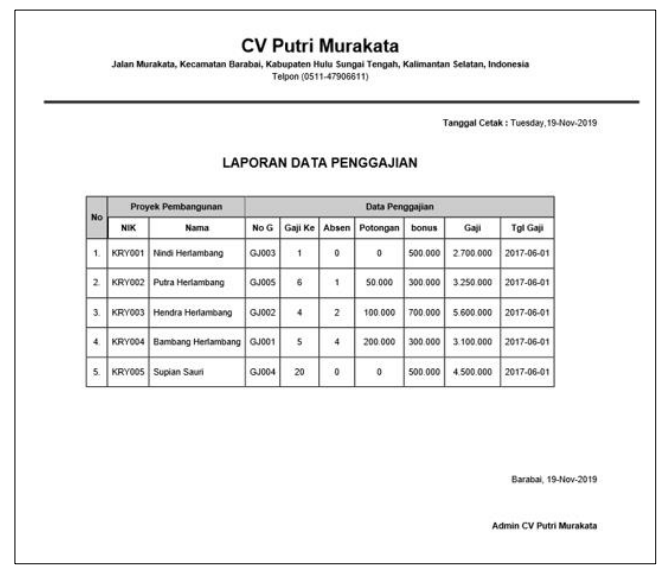

Gambar 28. Laporan Data Penggajian

\section{KESIMPULAN}

Kesimpulan yang didapatkan setelah melakukan implementasi dan beberapa pengujiian, maka dapat dipaparkan yaitu:

1. Aplikasi memudahkan kantor CV. Puteri Murakata dalam mengelola pencatatan pembukuan dengan cepat, dan akurat.

2. Prosedur pengelolaan pelaksanaan proyek pada CV. Puteri Murakata yang dibuat berjalan dengan baik sebagaimana yang diharapkan.

3. Aplikasi pengelolaan pelaksanaan proyek berpengaruh terhadap kinerja kontraktor dalam menyelesaikan proyek tepat waktu yang telah ditentukan.

\section{DAFTAR PUSTAKA}

1] Mifta, A. Dampak Perkembangan Teknologi, Informasi dan Komunikasi Terhadap Prilaku Remaja di Indonesia. JOURNAL TEKNIK TEKNOLOGI, 1-8. 2018

2] Peranginangin. Aplikasi WEB dengan PHP dan MySQL. Yogyakarta: ANDI. 2006.
3] Pressman, R. Rekayasa Perangkat Lunak - Buku Satu, Pendekatan Praktisi (Edisi 7). Yogyakarta: ANDI. 2012

4] Sunyoto, A. Pemrograman Database dengan Visual Basic dan Microsoft SQL. Yogyakarta: ANDI. 2007

5] Utami, E. Konsep Dasar Pengolahan dan Pemrograman Database dengan SQ1 Server, Ms. Access, dan Ms. Visual Basic. Yogyakarta: ANDI. 2005

6] Wikipedia. (2019, September 7). HTML. Retrieved Oktober 1, 2019, from Wikipedia: https://id.wikipedia.org/wiki/HTML

7] Wikipedia. (2019, Oktober 1). MySQL. Retrieved from Wikipedia: https://id.wikipedia.org/wiki/MySQL

8] Wikipedia. (2019, September 20). PHP. Retrieved Oktober 1, 2019, from Wikipedia: https://id.wikipedia.org/wiki/PHP 